\title{
Effects of exercise on sexual function and central mechanism in the streptozotocin-induced diabetic rats
}

\author{
Jae-Min Lee', Tae-Woon Kim', Hye-Sang Park'1, Sang-Seo Park', Mal-Soon Shin², Yun-Hee Sung ${ }^{3}$, Tae-Beom Seo ${ }^{4}$, Young-Pyo Kim ${ }^{4 * *}$ \\ 'Department of Physiology, College of Medicine, Kyung Hee University, Seoul, Korea \\ ${ }^{2}$ School of Global Sport Studies, Korea University, Sejong, Korea \\ ${ }^{3}$ Department of Physical Therapy, Kyungnam University, Changwon, Korea \\ ${ }^{4}$ Department of Kinesiology, College of Natural Science, Jeju National University, Jeju, Korea
}

Diabetes mellitus is associated with the impairment of sexual function including desire and orgasmic dysfunction. Sexual dysfunction in the diabetes mellitus is due to a selective defect of the nitric oxide synthase (NOS) within paraventricular nucleus (PVN). c-Fos is an immediate early gene and c-Fos expression represents neuronal activity in response to various stimuli. In the present study, we investigated the effects of treadmill exercise on sexual behaviors and the expressions of NOS and c-Fos in the PVN were evaluated using streptozotocin (STZ)-induced diabetic rats. Diabetes mellitus was induced by intraperitoneal injection of STZ. The rats in the treadmill exercise groups were made to run on a treadmill for 30 min once a day during 4 weeks. Male sexual behaviors were evaluated by recording the number of mounting, intromission, and ejaculation frequency. The present results revealed that treadmill exercise ameliorated sexual dysfunction in the STZ-induced diabetic rats. Treadmill exercise restored the contents of NOS and c-Fos in the PVN. The improving effect of treadmill exercise on sexual function can be considered as the neuronal activating effect of exercise through increasing expressions of $\mathrm{NO}$ and c-Fos.

Keywords: Diabetes mellitus, Treadmill exercise, Sexual dysfunction, Nitric oxide, c-Fos, Paraventricular nucleus

\section{INTRODUCTION}

Characteristic symptoms of diabetes mellitus are thirst, polyuria, blurring of vision, weight loss, and polyphagia (American Diabetes Association, 2010). Diabetes mellitus is associated with the impairment of sexual function including desire and orgasmic dysfunction (Lewis et al., 2004; Malavige and Levy, 2009). Diabetes mellitus patients suffer ejaculatory disorder and erectile dysfunction (Bhasin et al., 2007).

Erectile dysfunction is characterized by a consistent or recurrent inability to maintain penile erection (Hatzimouratidis and Hatzichristou, 2007). The hypothalamic paraventricular nucleus $(\mathrm{PVN})$ is responsible for controlling appetite, metabolic balance, cardiovascular regulation, and sexual behavior and known to be involved in centrally mediated penile erection (Zheng et al.,
2007). Nitric oxide (NO) is synthesized from the L-arginine by NO synthase (NOS), and NO regulates sexual and erectile function by strongly relaxing smooth muscle cells of male genitalia. The reduction of NO level in the streptozotocin (STZ)-induced diabetic model is associated with the lack of NOS activity (Escrig et al., 2002). Sexual dysfunction in the diabetes mellitus is due to a selective defect of the NOS within PVN (Zheng et al., 2011). Nicotinamide adenine dinucleotide phosphate-diaphorase (NADPH-d) is a histochemical maker specific for NOS, and the number of NADPH-d was decreased in the STZ-induced diabetic rats (Jang et al., 2003a).

c-Fos is an immediate early gene and c-Fos expression represents neuronal activity in response to various stimuli. c-Fos expression in the hippocampus was reduced in the STZ-induced diabetic rats (Jang et al., 2003b; Jee et al., 2008). Physical exercise

\footnotetext{
${ }^{*}$ Corresponding author: Young-Pyo Kim (D) https://orcid.org/0000-0001-6662-1393 Department of Kinesiology, College of Natural Science, Jeju National University, 102 Jejudaehak-ro, Jeju 63243, Korea

Tel: +82-64-754-3584, Fax: +82-64-757-1752, E-mail: kimyp@jejunu.ac.kr Received: January 4, 2018 / Accepted: February 10, 2018
}

This is an Open Access article distributed under the terms of the Creative Commons Attribution Non-Commercial License (http://creativecommons.org/licenses/by-nc/4.0/) which permits unrestricted non-commercial use, distribution, and reproduction in any medium, provided the original work is properly cited. 
is known to increase c-Fos expression at the most areas in the central nervous system (Kumada et al., 2017; Lee et al., 2003).

Exercise has been considered as an important intervention for the management of diabetes mellitus (Castaneda et al., 2002). Many studies suggested the effectiveness of physical exercise on improving sexual function in patients with diabetes mellitus (Adeniyi et al., 2010; Malavige et al., 2015). However, the effect of treadmill exercise on NO expression in relation with diabetes mellitus was not clarified. In the present study, we investigated the effect of treadmill exercise on sexual behaviors and the expressions of NADPH-d, neuronal NOS (nNOS), and c-Fos in the PVN were evaluated using STZ-induced diabetic rats.

\section{MATERIALS AND METHODS}

\section{Animals and treatments}

Male Sprague-Dawley rats $(250 \pm 10 \mathrm{~g}, 9$ weeks in age) were used, and all experimental procedures were conformed to the regulations stipulated by the National Institutes of Health and the guidelines of the Korean Academy of Medical Science. This study was approved by the Kyung Hee University Institutional Animal Care and Use Committee (Seoul, Korea, KHUASP[SE]-17-098). The rats were divided into four groups ( $\mathrm{n}=10$ in each group): Control group, treadmill exercise group, STZ-induced diabetes group, STZ-induced diabetes and treadmill exercise group. To induce diabetic animal model, $50-\mathrm{mg} / \mathrm{kg}$ STZ (Sigma Chemical Co., St. Louis, MO, USA) was an intraperitoneally injected.

\section{Treadmill exercise protocol}

The rats in the exercise groups were made to run on a treadmill for 30 min once a day for 4 weeks, starting 9 weeks after birth, according to the previously described method (Shin et al., 2017). The treadmill exercise load consisted of running at $5 \mathrm{~m} / \mathrm{min}$ for the first of $5 \mathrm{~min}$, at $7 \mathrm{~m} / \mathrm{min}$ for the next $5 \mathrm{~min}$, and then at 9 $\mathrm{m} / \mathrm{min}$ for the last $20 \mathrm{~min}$ at 0 degree of inclination.

\section{Sexual behavior test}

Four weeks after starting treadmill exercise, sexual behavior test was conducted in a dimly lighted room, using observation cages $(60 \mathrm{~cm} \times 50 \mathrm{~cm} \times 30 \mathrm{~cm})$. Ovariectomized female rats were used as lures for the male sexual behavior. Female rats were made estrous by subcutaneous injection of $20 \mathrm{mg} / \mathrm{kg}$ of estradiol benzoate $48 \mathrm{hr}$ before testing and $1 \mathrm{mg} / \mathrm{kg}$ of progesterone $6 \mathrm{hr}$ before testing. Male sexual behaviors were evaluated by recording the number of mounting, intromission, and ejaculation frequency, accord- ing to the previously described method (Shin et al., 2016).

\section{NAPDH-d histochemistry}

For NADPH-d activity, the sections were stained, according to a previously described protocol (Jang et al., 2003a; Jang et al., 2005). Eight sections on average were collected from each brain within the in the hypothalamic PVN. Free-floating sections were incubated at $37^{\circ} \mathrm{C}$ for $1 \mathrm{hr}$ in $0.1 \mathrm{M} \mathrm{PB}$ containing $0.3 \%$ Triton $\mathrm{X}-100,0.1-\mathrm{mg} / \mathrm{mL}$ nitroblue tetrazolium, and $0.1-\mathrm{mg} / \mathrm{mL}$ $\beta$-NADPH (Sigma Chemical Co.). The sections were then washed 3 times with phosphate-buffered saline (PBS) and mounted onto gelatine-coated slides. The slides were air-dried overnight at room temperature, and coverslips were mounted using Permount (Fisher Scientific, Fair Lawn, NJ, USA).

\section{Immunohistochemistry}

Immunohistochemistry for the c-Fos and nNOS-positive cells in the PVN was performed, according to a previously described protocol (Hong et al., 2014; Jang et al., 2005). The sections were then incubated in $0.05 \mathrm{M}$ PBS for $5 \mathrm{~min}$ and washed three times using 0.05 M PBS. Free-floating sections were first incubated in $3 \% \mathrm{H}_{2} \mathrm{O}_{2}$ for $30 \mathrm{~min}$. Next, the sections were incubated in blocking solution for $2 \mathrm{hr}$ at room temperature. The sections were then incubated overnight with rabbit anti-c-Fos antibody (1:1,000; Santa Cruz Biotechnology, Santa Cruz, CA, USA), mouse anti-nNOS antibody (1:1,000; Santa Cruz Biotechnology). The biotinylated horse anti-mouse and goat anti-rabbit IgG secondary antibody (1:200; Vector Laboratories, Burlingame, CA, USA). Next, the sections were incubated with avidin-biotin-peroxidase complex (Vector Laboratories) for $1 \mathrm{hr}$ at room temperature. For staining, the sections were incubated in a solution consisting of $0.02 \%$ diaminobenzidine and $0.03 \% \mathrm{H}_{2} \mathrm{O}_{2}$ in $50 \mathrm{mM}$ Tris- $\mathrm{HCl}(\mathrm{pH}, 7.6)$ for approximately $5 \mathrm{~min}$, after which they were then washed with PBS and mounted onto gelatin-coated slides, and coverslips were mounted using Permount (Fisher Scientific).

\section{Data analysis}

The numbers of NADPH-d-positive and nNOS-positive cells were counted using a microscope (Olympus, Tokyo, Japan). The results expressed as the mean \pm standard error of the mean. For the comparison among the groups, one-way analysis of variance and Duncan post hoc test were performed with $P<0.05$ as an indication of statistical significance. 

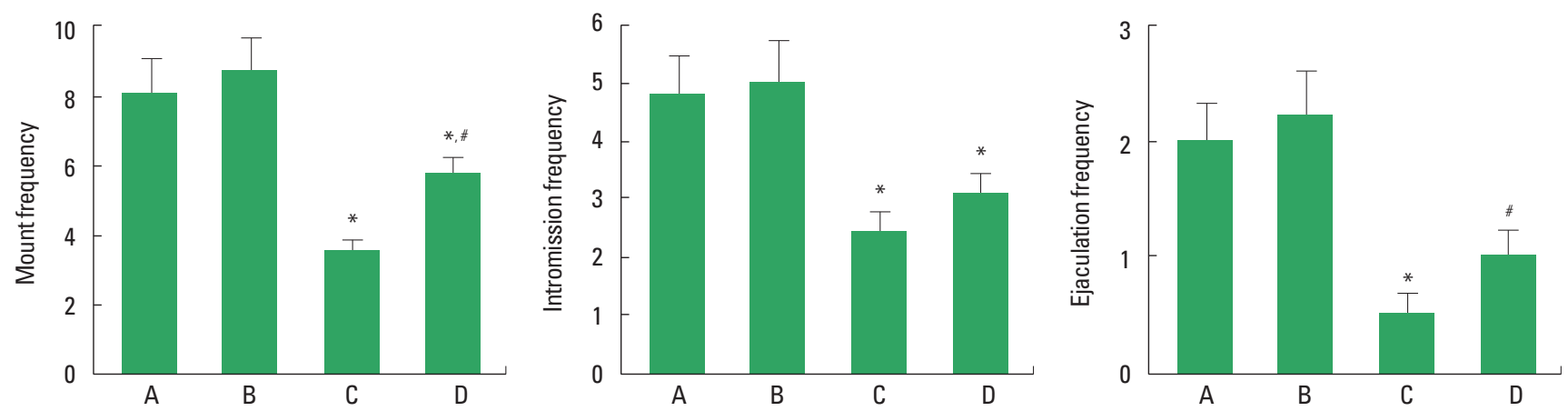

Fig. 1. Effect of treadmill exercise on sexual behaviors. A, control group; B, treadmill exercise group; C, streptozotocin (STZ)-induced diabetes group; D, STZ-induced diabetes and treadmill exercise group. The data are presented as the mean \pm standard error of the mean. ${ }^{*} P<0.05$ compared with the control group. ${ }^{\sharp} P<0.05$ compared with the STZ-induced diabetes group.

\section{RESULTS}

\section{Sexual behavior test}

The latencies of the sexual behavior test are presented in Fig. 1. Ejaculation frequency, mount frequency, and intromission frequency were lower in the STZ-induced diabetic rats compared to the control rats. In contrast, treadmill exercise increased ejaculation frequency, mount frequency, and intromission frequency in the STZ-induced diabetic rats.

\section{NADPH-d-positive cells in the hypothalamic PVN}

Photomicrographs of NADPH-d-positive cells in the PVN are presented in Fig. 2. The number of NADPH-d-positive cells in the PVN was lower in the STZ-induced diabetic rats compared to the control rats. In contrast, treadmill exercise increased the number of NADPH-d-positive cells in the STZ-induced diabetic rats.

\section{nNOS expression in the hypothalamic PVN}

Photomicrographs of nNOS-positive cells in the PVN are presented in Fig. 3. Expression of nNOS in the PVN was lower in the STZ-induced diabetic rats compared to the control rats. In contrast, treadmill exercise increased nNOS expression in the STZ-induced diabetic rats.

\section{c-Fos expression in the hypothalamic PVN}

Photomicrographs of c-Fos-positive cells in the PVN are presented in Fig. 4. Expression of c-Fos in the PVN was lower in the STZ-induced diabetic rats compared to the control rats. In contrast, treadmill exercise increased c-Fos expression in the STZ-induced diabetic rats.
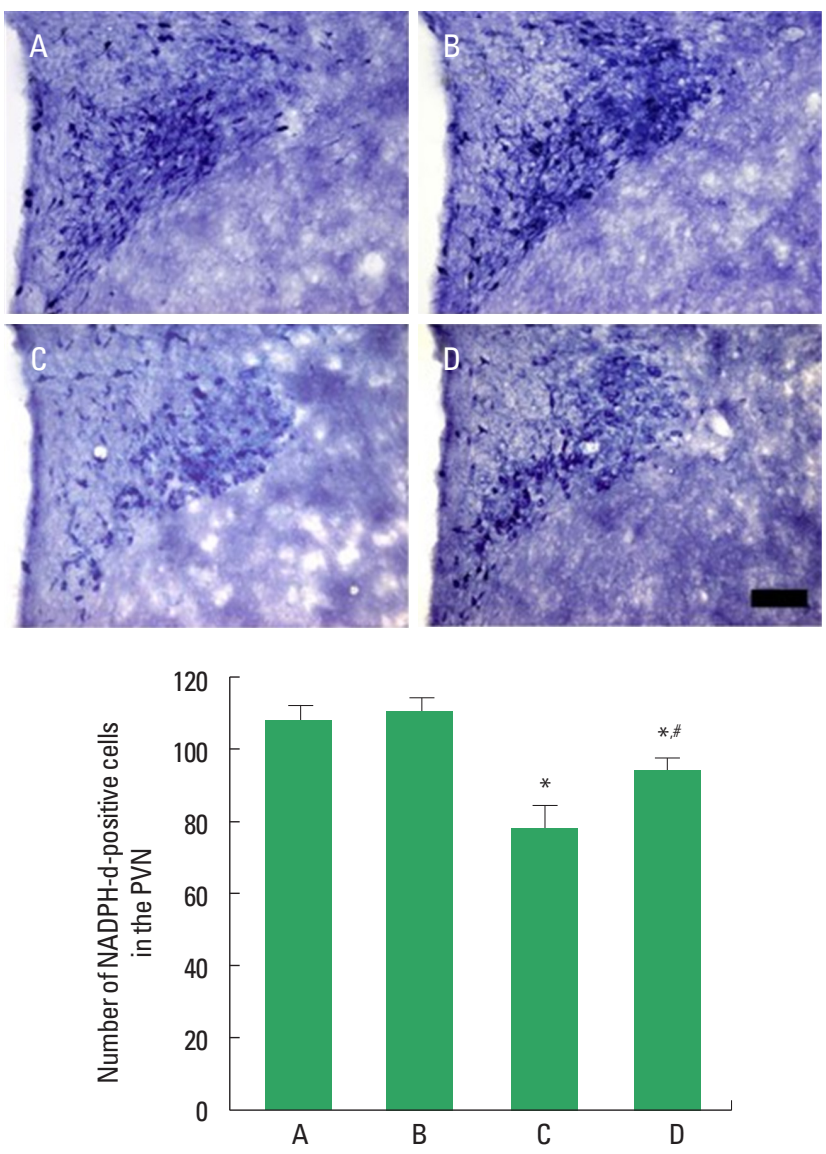

Fig. 2. Effect of treadmill exercise on nitric oxide synthase (NOS) expression. Upper panel: photomicrographs of nicotinamide adenine dinucleotide phosphate-diaphorase (NADPH-d)-positive cells. The scale bar represents $100 \mu \mathrm{m}$. Lower panel: number of NADPH-d-positive cells in each group. PVN, paraventricular nucleus; $A$, control group; $B$, treadmill exercise group; $C$, streptozotocin (STZ)-induced diabetes group; D, STZ-induced diabetes and treadmill exercise group. The data are presented as the mean \pm standard error of the mean. ${ }^{*} P<0.05$ compared with the control group. ${ }^{\#} P<0.05$ compared with the STZ-induced diabetes group. 

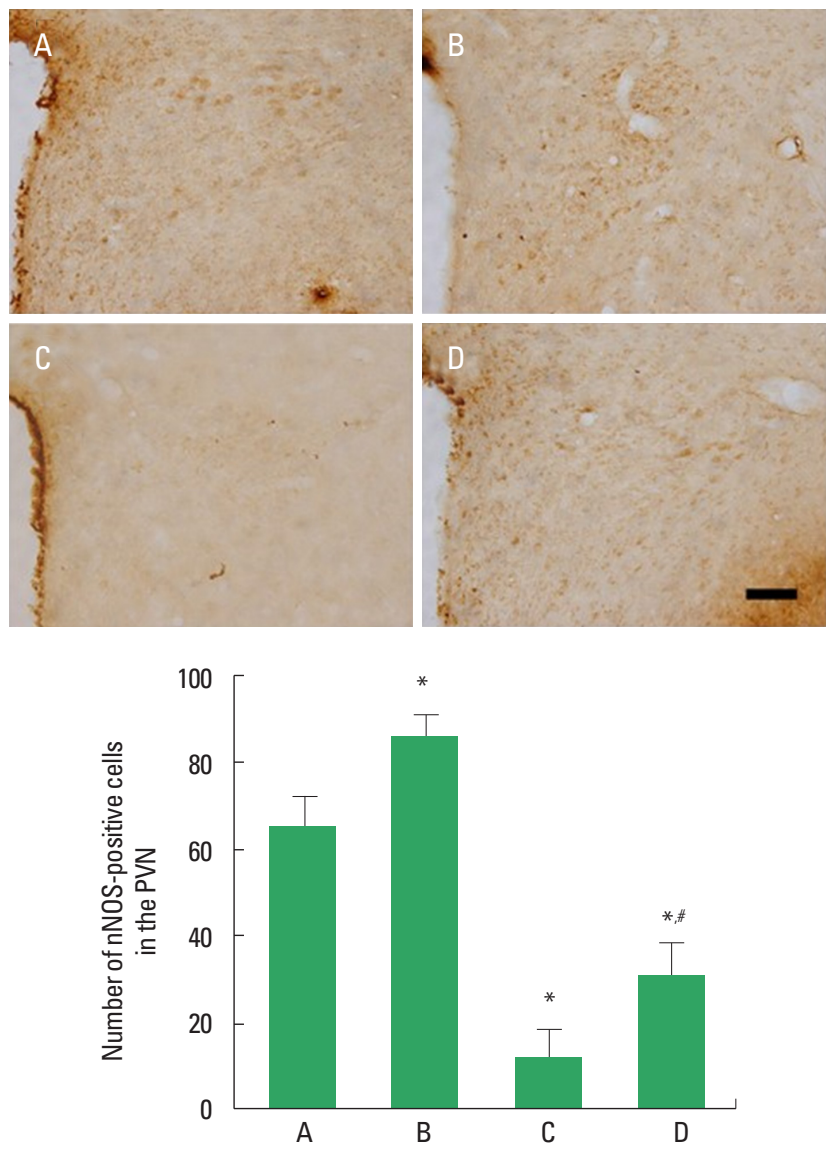

Fig. 3. Effect of treadmill exercise on neuronal nitric oxide synthase (nNOS) expression. Upper panel: photomicrographs of nNOS-positive cells. The scale bar represents $100 \mu \mathrm{m}$. Lower panel: number of nNOS-positive cells in each group. PVN, paraventricular nucleus; $A$, control group; $B$, treadmill exercise group; $C$, streptozotocin (STZ)-induced diabetes group; D, STZ-induced diabetes and treadmill exercise group. The data are presented as the mean \pm standard error of the mean. ${ }^{*} P<0.05$ compared with the control group. ${ }^{\#} P<0.05$ compared with the STZ-induced diabetes group.

\section{DISCUSSION}

Sexual dysfunction is one of the frequently encountered complications in the diabetic patients (Lewis et al., 2004). Patients with diabetes mellitus have an increased risk of impotence (Grover et al., 2006). Erectile dysfunction in middle-aged men is often an early event in endothelial damage, and physical activity is able to improve both erectile and endothelial dysfunction (La Vignera et al., 2012). Exercise training alleviated the impairment of endothelial and nitrergic corpus cavernosum in STZ-induced diabetic rats (Claudino et al., 2011). They suggested that regular exercise might be an important strategy for preventing erectile dysfunction associated with diabetes mellitus by re-establishment of the
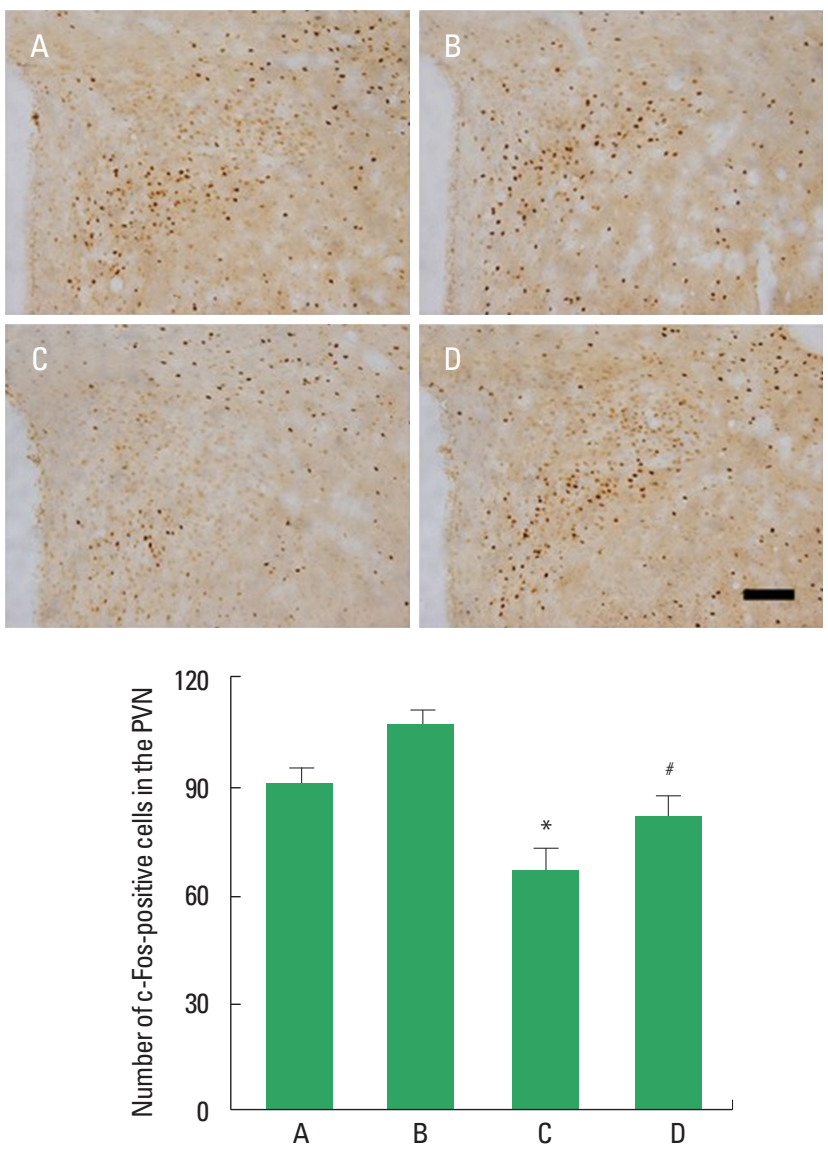

Fig. 4. Effect of treadmill exercise on c-Fos expression. Upper panel: photomicrographs of c-Fos-positive cells. The scale bar represents $100 \mu \mathrm{m}$. Lower panel: number of c-Fos-positive cells in each group. PVN, paraventricular nucleus; A, control group; B, treadmill exercise group; C, streptozotocin (STZ)-induced diabetes group; D, STZ-induced diabetes and treadmill exercise group. The data are presented as the mean \pm standard error of the mean. ${ }^{*} P<0.05 \mathrm{com}$ pared with the control group. ${ }^{\#} P<0.05$ compared with the STZ-induced diabetes group.

balance between $\mathrm{NO}$ production and its inactivation (Claudino et al., 2011). Erectile dysfunction was associated with physical inactivity, irrespective of diabetes status (Malavige et al., 2015).

In the present study, ejaculation frequency, mount frequency, and intromission frequency were decreased in the STZ-induced diabetic male rats. Treadmill exercise improved these parameters of the sexual behaviors in STZ-induced diabetic male rats. The present results demonstrated that treadmill exercise could alleviate sexual dysfunction caused by diabetes mellitus.

$\mathrm{NO}$ is an important mediator that regulates erectile function by inducing vasodilation (Bivalacqua et al., 2004). Blunted NO mechanism within the PVN may contribute to erectile dysfunction observed in diabetes mellitus (Zheng et al., 2007). Exercise is 
useful tool for increasing NOS expression in the PVN (Kim et al., 2003). Exercise up-regulated nNOS expression within the PVN and improved the central component of the erectile dysfunction in diabetes mellitus (Zheng et al., 2011). The level of neuronal NOS in the PVN was decreased in STZ-induced type 1 diabetic rats (Zheng et al., 2013).

In the present study, the numbers of NADPH-d-positive and nNOS-positive cells in the PVN were decreased in the STZ-induced diabetic rats. Treadmill exercise increased these numbers in the STZ-induced diabetic rats. The present results demonstrated that treadmill exercise restored the content of NO in STZ-induced diabetic rats.

c-Fos expression represents neuronal activity and plays a crucial role in the brain development (Sim et al., 2008). c-Fos expression in the brain was decreased in the STZ-induced diabetic rats (Jee et al., 2008). Treadmill increased c-Fos expression that is associated with neuroplasticity, thereby improved spatial memory (You et al., 2009).

In the present study, c-Fos expression in the PVN was decreased in the PVN was decreased in the STZ-induced diabetic rats. Treadmill exercise increased c-Fos expression in the STZ-induced diabetic rats. The present results demonstrated that treadmill exercise restored the content of c-Fos in the STZ-induced diabetic rats.

The present results showed that treadmill exercise ameliorated sexual dysfunction in the STZ-induced diabetic rats. The improving effect of treadmill exercise on sexual function can be considered as the neuronal activating effect of exercise through increasing expressions of $\mathrm{NO}$ and c-Fos.

\section{CONFLICT OF INEREST}

No potential conflict of interest relevant to this article was reported.

\section{ACKNOWLEDGMENTS}

This work was supported by the Ministry of Education of the Republic of Korea and the National Research Foundation of Korea (NRF-2015S1A5A2A01013486).

\section{REFERENCES}

Adeniyi AF, Adeleye JO, Adeniyi CY. Diabetes, sexual dysfunction and therapeutic exercise: a 20 year review. Curr Diabetes Rev 2010;6:201-
206.

American Diabetes Association. Diagnosis and classification of diabetes mellitus. Diabetes Care 2010;33 Suppl 1:S62-S69.

Bhasin S, Enzlin P, Coviello A, Basson R. Sexual dysfunction in men and women with endocrine disorders. Lancet 2007;369:597-611.

Bivalacqua TJ, Champion HC, Usta MF, Cellek S, Chitaley K, Webb RC, Lewis RL, Mills TM, Hellstrom WJ, Kadowitz PJ. RhoA/Rho-kinase suppresses endothelial nitric oxide synthase in the penis: a mechanism for diabetes-associated erectile dysfunction. Proc Natl Acad Sci US A 2004;101:9121-9126.

Castaneda C, Layne JE, Munoz-Orians L, Gordon PL, Walsmith J, Foldvari M, Roubenoff R, Tucker KL, Nelson ME. A randomized controlled trial of resistance exercise training to improve glycemic control in older adults with type 2 diabetes. Diabetes Care 2002;25:2335-2341.

Claudino MA, Delbin MA, Franco-Penteado CF, Priviero FB, De Nucci G, Antunes E, Zanesco A. Exercise training ameliorates the impairment of endothelial and nitrergic corpus cavernosum responses in diabetic rats. Life Sci 2011;88:272-277.

Escrig A, Marin R, Abreu P, Gonzalez-Mora JL, Mas M. Changes in mating behavior, erectile function, and nitric oxide levels in penile corpora cavernosa in streptozotocin-diabetic rats. Biol Reprod 2002;66:185189.

Grover SA, Lowensteyn I, Kaouache M, Marchand S, Coupal L, DeCarolis E, Zoccoli J, Defoy I. The prevalence of erectile dysfunction in the primary care setting: importance of risk factors for diabetes and vascular disease. Arch Intern Med 2006;166:213-219.

Hatzimouratidis K, Hatzichristou D. Sexual dysfunctions: classifications and definitions. J Sex Med 2007;4:241-250.

Hong H, Kim CJ, Kim JD, Seo JH. $\beta$-glucan reduces exercise-induced stress through downregulation of c-Fos and c-Jun expression in the brains of exhausted rats. Mol Med Rep 2014;9:1660-1666.

Jang MH, Chang HK, Shin MC, Lee TH, Kim YP, Kim EH, et al. Effect of ginseng radix on c-Fos expression in the hippocampus of streptozotocin-induced diabetic rats. J Pharmacol Sci 2003a;91:149-152.

Jang MH, Lee MH, Kim H, Lee SJ, Sim YJ, Kim CJ, Park SK, Kim J, Kim EH. Maternal alcohol administration suppresses expression of nitric oxide synthase in the hippocampus of offspring rats. J Pharmacol Sci 2005;98:459-462.

Jang MH, Shin MC, Lim BV, Kim HB, Kim YP, Kim EH, Kim H, Shin MS, Kim SS, Kim CJ. Acupuncture increases nitric oxide synthase expression in hippocampus of streptozotocin-induced diabetic rats. Am J Chin Med 2003b;31:305-313.

Jee YS, Ko IG, Sung YH, Lee JW, Kim YS, Kim SE, Kim BK, Seo JH, Shin MS, Lee HH, Cho HJ, Kim CJ. Effects of treadmill exercise on memory and c-Fos expression in the hippocampus of the rats with intracere- 
broventricular injection of streptozotocin. Neurosci Lett 2008;443:188192.

Kim SS, Kim H, Lee SJ, Chang HK, Shin MC, Jang MH, Shin MS, Kim CJ. Treadmill exercise suppresses food-deprivation-induced increase of nitric oxide synthase expression in rat paraventricular nucleus. Neurosci Lett 2003;353:41-44.

Kumada N, Koba S, Hanai E, Watanabe T. Distribution of Fos-immunoreactive cells in the ventral part of rat medulla following voluntary treadmill exercise. Auton Neurosci 2017;208:80-87.

La Vignera S, Condorelli R, Vicari E, D'Agata R, Calogero AE. Physical activity and erectile dysfunction in middle-aged men. J Androl 2012; 33:154-161.

Lee MH, Kim H, Lim BV, Chang HK, Lee TH, Jang MH, Shin MC, Lee J, Shin MS, Kim CJ. Naloxone potentiates treadmill running-induced increase in c-Fos expression in rat hippocampus. Life Sci 2003;73:31393147.

Lewis RW, Fugl-Meyer KS, Bosch R, Fugl-Meyer AR, Laumann EO, Lizza E, Martin-Morales A. Epidemiology/risk factors of sexual dysfunction. J Sex Med 2004;1:35-39.

Malavige LS, Levy JC. Erectile dysfunction in diabetes mellitus. J Sex Med 2009;6:1232-1247.

Malavige LS, Wijesekara P, Ranasinghe P, Levy JC. The association between physical activity and sexual dysfunction in patients with diabetes mellitus of European and South Asian origin: The Oxford Sexual Dysfunction Study. Eur J Med Res 2015;20:90.

Shin MS, Chung KJ, Ko IG, Kim SH, Jin JJ, Kim SE, Lee JM, Ji ES, Kim
TW, Cho HS, Kim CH, Cho YS, Kim CJ, Kim KH. Effects of surgical and chemical castration on spatial learning ability in relation to cell proliferation and apoptosis in hippocampus. Int Urol Nephrol 2016; 48:517-527.

Shin MS, Park SS, Lee JM, Kim TW, Kim YP. Treadmill exercise improves depression-like symptoms by enhancing serotonergic function through upregulation of 5-HT(1A) expression in the olfactory bulbectomized rats. J Exerc Rehabil 2017;13:36-42.

Sim YJ, Kim H, Shin MS, Chang HK, Shin MC, Ko IG, Kim KJ, Kim TS, Kim BK, Rhim YT, Kim S, Park HY, Yi JW, Lee SJ, Kim CJ. Effect of postnatal treadmill exercise on c-Fos expression in the hippocampus of rat pups born from the alcohol-intoxicated mothers. Brain Dev 2008;30:118-125.

You JS, Kim CJ, Kim MY, Byun YG, Ha SY, Han BS, Yoon BC. Long-term treadmill exercise-induced neuroplasticity and associated memory recovery of streptozotocin-induced diabetic rats: an experimenter blind, randomized controlled study. NeuroRehabilitation 2009;24:291-297.

Zheng H, Bidasee KR, Mayhan WG, Patel KP. Lack of central nitric oxide triggers erectile dysfunction in diabetes. Am J Physiol Regul Integr Comp Physiol 2007;292:R1158-R1164

Zheng H, Liu X, Patel KP. Centrally mediated erectile dysfunction in rats with type 1 diabetes: role of angiotensin II and superoxide. J Sex Med 2013;10:2165-2176.

Zheng H, Mayhan WG, Patel KP. Exercise training improves the defective centrally mediated erectile responses in rats with type I diabetes. J Sex Med 2011;8:3086-3097. 